\title{
Evolutionary Psychology, Biology, and Cultural Evolution $^{1}$
}

\author{
Richard E. Nisbett ${ }^{2}$ \\ University of Michigan
}

Evolutionary approaches to behavior, so far from indicating that human behavioral patterns must be universal and "wired," actually provide us with good reasons for expecting cultural diversity and good tools for showing how it might develop. Even gender-role related behavior may be very plastic. Highly "macho" male behavior may be an adaptation to dangerous ecological and economic constraints. Similarly, homicide rates differ massively from culture to culture and may be under the control of specifiable ecological and economic constraints.

Recently a new field calling itself "evolutionary psychology" has become prominent on the scientific stage. The concerns and approaches of this field are continuous with predecessor fields such as ethology and sociobiology and to a lesser extent population genetics and behavioral genetics. The field is concerned with the adaptive problems that humans faced over the course of evolution, and with the behavioral mechanisms that evolved in response to selection pressures. Some examples include work on criteria of mate selection by David Buss (1989), work on postulated cognitive mechanisms for solving characteristic social and economic problems (for example, Barkow, Cosmides, \& Tooby, in press), work positing the fitness advantages of anxiety (Buss, 1990) and work positing the fitness advantages of an unconscious mind (Nesse, 1990). The characteristic argument of this discipline

\footnotetext{
${ }^{1}$ Adapted from a symposium talk given at the annual meeting of the Society for Experimental Social Psychology, October 13, 1990, Buffalo, New York. David Buss, Nancy Cantor, and Claude Steele made helpful comments on earlier versions of this paper.

${ }^{2}$ Address all correspondence to Professor Richard E. Nisbett, Institute for Social Research, University of Michigan, P.O. Box 1248, Ann Arbor, Michigan 48106-1248.
} 
is a materialistic or functional one. It considers that the ecology or economy or characteristic patterns of social relations would have made certain behaviors useful, and that there may be evidence that these behaviors are prewired or at least "prepared" in the sense that people are likely to emit them, given certain conditions, because of biological mechanisms that underlie them. Or the argument begins in the opposite direction with apparently endemic or striking behavior patterns and a search is made for a materialistic or functional argument to elucidate the behavior. The assumption is that a biological or "prewired" mechanism underlies the behavior pattern.

Whenever a new field shows as much vigor and enthusiasm as evolutionary psychology does, its neighbors are likely to get nervous. And I do think social psychologists are nervous in various ways about evolutionary psychology and other biological approaches to behavior. There are three sources of concern that I have spotted. The first is that very broad claims are often made on the basis of little that most social psychologists would regard as evidence. The second is plain old-fashioned turf protection. Evolutionary psychologists seem to be mowing much of the same grass that social psychologists have long regarded as their own, and the question naturally arises as to who is going to own the intellectual territory here. The third concern is about values. Outsiders often think that evolutionary psychologists believe that certain behavior patterns are fixed or hard-wired. Social psychologists like to believe in flexibility in general, and they certainly don't want to believe in fixedness of the kind of behaviors that evolutionary psychologists discuss most frequently, such as aggression and behavior related to gender roles.

I would like to take up each of these points in turn. In a word, I want to argue that each of these concerns has been exaggerated, and that evolutionary psychology and biological perspectives on behavioral science in general offer social psychologists valuable tools, and (even though my chauvinism makes me hesitate to say it) theoretical guidance for studying some problems of great interest to us.

First, and most briefly, I will say that I share the impatience of many social psychologists with the scientific standards characteristic of many evolutionary psychology pronouncements. Sometimes the argument form can be little more, at base, than "I now assert the following bold proposition p." Even where there is evidence, the arguments based on it can be extraordinarily thin. My own pet peeve is against studies that show that people handle problem A somewhat better than problem B and then assert that there must be privileged wiring for solving A. Nothing short of massive differences, such as are found for the leaning of stimulus associations that are differently "prepared" (Seligman, 1970), could create a presumption of 
prewiring, in my view. But I think we should resist the annoyance produced by this sort of thing. A field deserves to be judged by its best achievements, and I think there are already several important ones by people working on evolutionary approaches to behavior, who include (in addition to psychologists) biologists, anthropologists, economists, and political scientists.

Second, there is the question of turf. In one way or another, this has been addressed by all of the contributors to this symposium. All seem basically agreed that the playing field in question is quite big enough for all contenders and that the two disciplines can make good use of each other. Cantor notes the heuristic value of evolutionary theory for social psychology and points out that an emphasis on the importance of social relations is at the very core of the perspective and therefore holds that "the evolutionary account can be a useful guide to important domains of human interaction" (Cantor, this issue, p. 248). Buss goes further and invites social psychologists to come and take their rightful place in the vanguard of evolutionary psychology (Buss, this issue). The rationale for this is that many of the most important adaptive problems were social in nature. Consequently, solutions to these problems were driving human evolution to a substantial degree. Thus the insights of social psychologists into the nature of the most fundamental social problems will translate into insights about the evolution of behavioral mechanisms. Brewer and Caporael (this issue) seem ready to take Buss up on his invitation. They apply insights from social psychology about the nature of group life and the relation of the individual to the group to an account of selection that implies that a form of group selection may actually have played a role in human evolution. I only wish to add my voice to this chorus. The two fields have a great deal to say to one another, and so far from feeling threatened by the emergence of evolutionary psychology, social psychologists should perceive it as an excellent opportunity to ply their trade with new tools, in company with people with a set of concerns that is similar enough to be congenial and a perspective that is novel enough to be stimulating.

The third frequently expressed concern of social psychologists is with the value implications of evolutionary approaches. As Cantor notes in this issue, it is easy to slide from a depiction of a type of behavior as having evolved to an assumption that it is "prewired" and inevitable and from there to a resigned acceptance that the behavior is the appropriate one for humans. I want to identify myself with many of the reservations that Cantor urges in her paper, and I want to spend most of the rest of my paper arguing that we may actually have less to fear about prewiring and fixedness from evolutionary psychology, and from population and behavioral genetics, than many have supposed. I want to deal with aspects of two topics - sex 
and aggression - that are very important for evolutionary psychologists because of their central role in fitness concerns.

Of all the theoretical notions stemming from evolutionary approaches to behavior, none seems so far-reaching to me as the concept of "parental investment." This concept accounts in a compelling way for differences in behavior across species and for sex differences in behavior within species (see, e.g., Buss, 1989). Fish have hundreds of thousands of fertilized eggs in a lifetime and pay not the slightest attention to their offspring. Bears have only a few offspring and the female bear is devoted to each of them for the first few years after they are born. Male bears are required only for insemination and have nothing to do with their offspring. Though human males are in general far more involved with the raising of their offspring than bears or most of our primate relatives, human males and females nevertheless have different degrees of parental investment. It is technically possible for male humans to act like male bears and have their genes perpetuated. Indeed, some male humans do just that. There are many implications of the notion of parental investment for gender differences: Female humans could be expected to be more nurturant, more interested in children and perhaps more interested in people in general, more selective of whom to mate with, and so on across a wide variety of traits that stereotypically differ across gender.

The parental investment notion thus could be seen to dictate relatively fixed gender roles. But in fact we already know from anthropological work completed early in this century that gender roles differ quite dramatically from one culture to another. This conclusion is associated with Margaret Mead's name more than with any other. Her descriptions of the societies that gave rise to her views have been sharply questioned in the recent anthropological literature, so it is important to note that the generalizations about extreme variability in gender role - from marked stereotypic male and female patterns to extremely muted, even quite difficult-to-detect gender differences - do not depend in any way on her work. The range has been documented repeatedly by other researchers (Gilmore, 1990).

But what are we to make of this diversity of gender-role patterns? Not that there are no biological constraints. As Buss notes in this issue, diversity does not indicate that biology makes no critical contribution. The diversity may reflect the fact that different circumstances trigger different behavioral forms, each of which is biologically prepared in some important sense.

Thus the diversity itself may be well understood in essentially evolutionary terms, which is the main point I wish to make about the utility of evolutionary psychology for social psychology. The way we understand the 
forces that shape human biology over the long haul may be useful for the way we understand the forces that push groups toward one or another behavior pattern over the short haul - a process that might be called "cultural evolution." In other words, the same material circumstances that gave rise to particular behavioral preparedness over the course of biological evolution may serve to prompt the emergence of these behavioral patterns in particular groups. This point is made in a concrete way in a fascinating book by David Gilmore entitled Manhood in the Making (1990). Gilmore begins his book by noting that the extreme masculine role variant we call machismo - the pattern of pride in sexual prowess, productivity in maleonly economic roles, and physical courage - is manifested by scores of cultures the world over. And yet, as we have just been noting, this pattern is by no means universal. Why do some cultures have it and others not?

Gilmore's (1990) answer is that the macho pattern is an adaptation to conditions of extreme risk associated with the means of production by males. A pattern of risk and high mortality characterize many economic systems. It is inherent, for example, in most systems that depend on herding animals. The neighbors are always going to find it tempting to steal the herd, and so a willingness to risk death to prevent such an occurrence can be an economic necessity. Social psychologists know that the sort of commitment to one's work is likely to be associated with valuing it highly, and hence the pride in productivity characteristic of people with risky occupations. Moreover, the high mortality rate associated with such systems puts a particularly high premium on the male pattern of sowing one's oats as opposed to (or perhaps in addition to) merely nurturing one small brood of offspring. Consistent with Gilmore's hypothesis, it has been noted that the Plains Indians of North America shifted their gender-role patterns with the coming of the horse (Lowie, 1954). Wealth now depended on the number of horses owned by an individual man and by a tribe. The tribes that used horses in their economies, like the Cheyenne and the Sioux, developed a new culture of militarism and glorification of physical valor that made them increasingly distinct from non-Plains people such as the Navajo, Hopi, and Iroqouis.

Gilmore's most persuasive evidence concerns the dramatic difference between two islands in the South Pacific - Truk and Tahiti. Both are the very image of the topical paradise, but they could not be more different with respect to gender roles. The male Trukese are violent fighters and compete with one another in physical contests and other acts of bravado (Marshall, 1979). They are expected to have many love affairs and they begin to sire children early. They are proud of their material possessions and compete with one another in building up a store of them. Women are required to be utterly submissive, and the men are extremely protective of 
them. Visitors to the island approach the women at their extreme peril. In contrast, Tahitian women, from their first encounter with Westerners, engaged in sexual activity with them with the full knowledge of the male population of the island. The males are little interested in material pursuits and do not compete with one another in them (Levy, 1973). Men are expected to be passive and submissive, and to ignore slights. There is no requirement to defend honor.

How to account for these differences? Gilmore (1990) does so by pointing to a dramatic difference in the means of obtaining food in the two cultures. The Tahitians fish in a lagoon at no risk to themselves and food is quite plentiful. The Trukese must obtain their fish on the open sea. When a Trukese male leaves for a day of fishing, there is a genuine possibility he will not return. Thus the fearless, aggressive macho style is an adaptation to danger. Males are taught to fear unmanliness more than death because this is the only way to encourage men to produce when there is great danger. Thus a muting of gender differences and surcease from the crushing requirements of assertive masculinity are a privilege of those societies that can put food on their tables without great risk.

Marvin Harris (1980) has proposed that a similar distinction may apply among hunter-gatherers. Where game is scarce, warfare may be common and sexual dimorphism in behavior relatively great. Aggressiveness against competitors in the search for large game, for example, may be relatively advantageous under scarcity. Thus scarcity may prompt the macho adaptation among males. Where there is abundance, male aggressiveness may be reduced and behavioral dimorphism may be less.

Thus an evolutionary approach, so far from requiring that important human behavior patterns be invariant, helps us to explain why the various diverse gender-related patterns of behavior are found where they are. It becomes a cultural evolution approach when it explains not the biologically based propensities but the circumstances that elicit those propensities that are part of the equipment of every human.

A concrete example of a cultural evolution account that is aided, indeed compelled, by biological considerations from both an evolutionary standpoint and a genetic standpoint comes from the study of cultural differences in homicide. Pop-psych (or rather pop-anthro) books of the 1960s with a biological orientation led many people to believe human nature was bred in tooth and claw and that violence might be endemic to the (male) human constitution. Once again, such a simplistic view flies in the face of human cultural variability. Here we are able to supply numbers having reasonably good accuracy in relation to the variation that exists worldwide. Cultures actually differ in their homicide rates by a factor of hundreds (Daly \& Wilson, 1988; Wolfgang \& Ferracuti (1967/1982)! The rates of 
homicide are low enough in some cultures, for example in Iceland and Israel, as to constitute great aberrations of extreme rarity. In others, for example, modern American inner cities, the rates are hundreds of times higher, and homicide is literally an everyday occurrence.

Again, how to account for such differences? Some people might be inclined to look to biological variability among human groups to account for the difference. But the biological evidence, and the evolutionary arguments, are quite opposed to such an account. Only 7 percent of human genetic variation is between race, while 85 percent of it is within the local group, with the remainder being variation between tribes or nations within a race (Lewontin, 1982). That is, there is substantially more variability between two individuals chosen at random from within a racial group than there is between the means of the two racial groups overall. Thus, the average genetic difference between two Icelandic villagers or between two black Detroiters is considerably greater than the mean difference between Iceland and the black population of Detroit. And though there is evidence for heritability of criminality of some kinds within European groups, the same evidence base suggests no heritability for homicide (see Wilson \& Herrnstein, 1985, for a review). Finally, the same genetic populations show dramatically different rates of homicide in different circumstances. Homicide rates in West Africa are not very high on a worldwide scale even though homicide rates of Americans of West African descent are among the highest in the world (Wolfgang \& Ferracuti, 1967/1982). Similarly, the rates for Europeans are generally very low on a worldwide scale, but are quite high in North America. Evolutionary considerations establish that the time scale of West African and European presence in the New World is vastly too short to have produced other than trivial biological differences from the parent populations.

Thus genetic and evolutionary arguments compel an account of homicide rate differences in nonbiological terms. My colleagues and I have begun to look at candidates for explaining differences in homicide rates (Nisbett, Polly, \& Lang, 1991). We have focused on the differences in homicide rates between the southern and northern regions of the United States. The rates have long been presumed to be due to a southern culture of violence, and we believe we have excellent evidence to support the contention that it is such a cultural difference rather than ecological or economic ones that produce the regional differences. We examined two different areas of the Great Plains having very similar ecologies, economies, and ethnic stock, having been settled primarily by English, Irish, and Germans. These regions are the Texas panhandle and the state of Nebraska. The major obvious difference between the regions is that the Europeans who settled the Texas panhandle came from the Upper South for the most 
part, while those who settled Nebraska came from the East, from other parts of the Midwest, and directly from Europe. Homicide rates are four times as high in the Texas panhandle as in Nebraska.

We are now beginning to explore whether these homicide rate differences have changed much over the past few generations. Whichever way it turns out, we will have learned something about cultural evolution. If the rates are converging, this will support the materialist view that cultures change in direct response to ecological and economic circumstances, which do not differ across the regions studied. If they have not changed, this would be more consistent with a social constructionist view that cultural factors can have substantial autonomy. Whichever result is obtained, however, the biological and evolutionary perspectives will have been crucial to making the case for a nonbiological, cultural account of some kind.

Thus I hope I have made my case that social psychologists have a great deal to gain by making use of evolutionary psychology and biological approaches to the study of behavior. These perspectives are not going to put us out of business or suggest severe constraints on human nature of a kind that would be repellent to most of us. On the contrary, they are going to be our allies in making sense of human uniformity and diversity alike.

\section{REFERENCES}

Barkow, L., Cosmides, L., \& Tooby (Eds.). (in press). The adapted mind. New York: Oxford University Press.

Brewer, M. B., \& Caporael, L. R. (this issue). Selfish genes vs. selfish people: Sociobiology as origin myth. Motivation and Emotion, 14, 237-243.

Buss, D. (1989). Sex differences in human mate preferences: Evolutionary hypotheses tested in 37 cultures. Behavioral and Brain Sciences, 12, 1-49.

Buss, D. (1990). The evolution of anxiety and social exclusion. Joumal of Social and Clinical Psychology, 9, 196-201.

Buss, D. (this issue). Evolutionary social psychology: Prospect and pitfalls. Motivation and Emotion, 14, 265-286.

Cantor, N. (this issue). Social psychology and sociobiology: What can we leave to evolution? Motivation and Emotion, 14, 245-254.

Daly, M., \& Wilson, M. (1988). Homicide. New York: Aldine de Gruyter.

Gilmore, D. D. (1990). Manhood in the making. New Haven, CT: Yale University Press.

Harris, M. (1980). Cultural materialism: The struggle for a science of culture. New York: Random House.

Levy, R. I. (1973). Tahitians: Mind and experience in the Society Islands. Chicago: University of Chicago Press.

Lewontin, R. (1982). Human diversity. New York: Scientific American Library.

Lowie, R. H. (1954). Indians of the plain. New York: McGraw-Hill.

Marshall, M. (1979). Weekend Warriors. Palo Alto, CA: Mayfield.

Nesse, R. M. (1990). The evolution of repression and the ego defenses. Journal of the American Academy of Psychoanalysis, 18, 260-286.

Nisbett, R. E., Polly, G., \& Lang, S. (1991). Homicide and cultural predispositions toward violence. Unpublished manuscript, University of Michigan. 
Seligman, M. E. P. (1970). On the generality of the laws of learning. Pychological Review, $77,406-418$.

Wilson, J. Q., \& Herrnstein, R. J. (1985). Crime and human nature. New York: Simon \& Schuster.

Wolfgang, M., \& Ferracuti, F. (1982). The subculture of violence. Beverly Hills, CA: Sage. (First published in 1967) 